\title{
Annoyance due to railway vibration at different times of the day
}

\author{
Eulalia Peris, James Woodcock, Gennaro Sica, Andrew T. Moorhouse, \\ and David C. Waddington \\ Acoustics Research Centre, University of Salford, Salford, Greater Manchester, M5 4WT, United Kingdom \\ E.Peris@edu.salford.ac.uk,J.S.Woodcock@edu.salford.ac.uk, \\ G.Sica@edu.salford.ac.uk,.A.T.Moorhouse@salford.ac.uk, \\ D.C.Waddington@salford.ac.uk
}

\begin{abstract}
The time of day when vibration occurs is considered as a factor influencing the human response to vibration. The aim of the present paper is to identify the times of day during which railway vibration causes the greatest annoyance, to measure the differences between annoyance responses for different time periods and to obtain estimates of the time of day penalties. This was achieved using data from case studies comprised of face-to-face interviews and internal vibration measurements $(N=755)$. Results indicate that vibration annoyance differs with time of day and that separate time of day weights can be applied when considering exposure-response relationships from railway vibration in residential environments.

(C) 2012 Acoustical Society of America

PACS numbers: $43.40 . \mathrm{Ng}, 43.50 . \mathrm{Qp}, 43.50 . \mathrm{Sr}$ [JM]

Date Received: November 7, 2011 Date Accepted: December 30, 2011
\end{abstract}

\section{Introduction}

Night-time and evening-time noises have a greater impact on annoyance in residential areas than daytime noise of the same level. A number of studies have shown different sensitivities with respect to noise exposure during the day, evening, and night (Fields, 1986a,b; Miedema et al., 2000; Schreckenberg and Meis, 2006). DENL, which includes different weighting factors in its calculation $(5 \mathrm{~dB}$ penalty for 19:00-23:00 $\mathrm{h}$, and 10 $\mathrm{dB}$ penalty for 23:00-7:00 h), was proven to be a good indicator for long term effects (annoyance). DENL is one of the EU indicators for environmental noise (EU/DG Environment, 2002) and it is currently used to illustrate exposure-response relationships for transportation noise (Miedema and Oudshoorn, 2001). Although there has been considerable discussion about time of day noise penalties, research about effects of vibration at different times of day is almost nonexistent. Taking into consideration previous time of day reaction to noise studies it could be assumed that vibration that is noticed during the daytime is less disturbing than vibration that is noticed and believed to have caused sleep disturbance during the night-time. Several studies have shown that vibration causes some sleep disturbance (Arnberg et al., 1990; Klæboe and Fyhri, 1999; Öhrström et al., 2009; Ögren and Öhrström, 2009) and annoyance reactions are more frequent during evenings and night-time (Öhrström, 1997). Therefore, it is probable that vibration annoyance follows a similar pattern as noise annoyance at different times of day, but currently there are no existing data showing how vibration time of day weights differ in the day, evening, and night for land-based transport annoyance.

The British standard BS 6472-1 (2008) recommends using the vibration dose value (VDV) as a vibration descriptor, which is a measure of the cumulative exposure to vibration during the measurement period and uses two frequency weighting curves for vertical and horizontal vibrations based on the human perception thresholds of vibration. The frequency-weighted root-mean-square (rms) acceleration is the preferred 
measure of vibration in the international standard ISO 2631-1 (1997). VDV takes into account the number of events, their duration, and their vibration level and rms takes account of the number of events and their level. However, there are no specific penalties determined in the calculation of these vibration descriptors for different times of day. The standard BS 6472-1 (2008) only recommends separate limit values for day and night times.

There is little research on annoyance response to vibration at different times of the day, thus the present study attempts to provide new information about time of day weighting. In this paper, the effects of railway vibration at different times of day, as well as the weights for each time period, are assessed by performing ordinal logistic regression on the survey and vibration data. The time of day annoyance ratings are related to vibration levels at corresponding times of day, and the exposure-response relationships from each are compared.

\section{Methods}

\subsection{Study design and sample}

The data in this paper relate to measurements of, and response to, railway vibration and were collected in the United Kingdom, specifically in the North-West of England and the Midlands area during 2009 and 2010 as part of the study "Human response to vibration in residential environments" performed by the University of Salford (Waddington et al., 2010).

The study sites were chosen to provide an overall representative and robust sample size, as well as to maximize the range of exposures to vibration and maximize the potential number of respondents. This was achieved by selecting sites that are within a range of distances from the railway, are exposed to different railway traffic and contain different kinds of properties. Mainly, the sites were identified according to their population density and distance from the vibration source. Properties within a distance of $100 \mathrm{~m}$ from the railway were targeted to ensure a relatively high and perceptible vibration level for the respondents.

Face to face questionnaires were used and the total number of completed questionnaires relating to railway vibration was 931 with associated high-quality vibration data being obtained internally within respondent's properties.

\subsection{Vibration exposure}

The measurement of vibration was carried out using Guralp CMG-5TD accelerometers and the measurement protocol employed in the field consisted of long term vibration monitoring at an external position (e.g., a garage or a shed) along with time synchronized short-term internal snapshot measurements. By determining the velocity ratio between the control and the internal measurements, an estimation of 24-h internal vibration exposure was obtained.

For each respondent, the frequency-weighted root-mean-square acceleration values (using the $W_{k}$ weighting curve, which applies to vertical vibration and demonstrates maximum sensitivity to vertical acceleration in the frequency range $4-12.5 \mathrm{~Hz}$ ) in accordance with ISO 2631-1 (1997) were calculated over $24 \mathrm{~h}$ and over three different time periods defined as daytime between 7:00 and 19:00 h, evening between 19:00 and 23:00 $\mathrm{h}$, and night between 23:00 and 7:00 $\mathrm{h}$.

\subsection{Questionnaire}

The study respondents self-assessed their degree of overall annoyance and their degree of annoyance during particular times the of day due to railway vibration on a fivepoint semantic scale, as recommended by the standard ISO/TS 15666 (2003) (Condie et al., 2009). In the survey, annoyance during different time periods was assessed, from respondents who stated being somehow annoyed by vibration, and through the following question: "Thinking about the last 12 months or so, when indoors at home, how bothered, annoyed, or disturbed have you been by feeling vibration or hearing or 
seeing things rattle, vibrate, or shake caused by the railway between day (from 7:00 a.m. to 7:00 p.m.), evening (from 7:00 p.m. to 11:00 p.m.), and night (from 11:00 p.m. to 7:00 a.m.), would you say not at all, slightly, moderately, very, or extremely?"

The respondents who stated they could not feel vibration were recoded to the lowest category of the five-point semantic annoyance scale. The annoyance response categories were converted to a scale ranging from 0 to 100 and centered to the midpoints of these categories. This conversion is based on the assumption that a set of categories divides the range from 0 to 100 into equally spaced intervals. Exposureresponse relationships are generally analyzed for the percentage of highly annoyed people (\%HA), which according to the ICBEN recommendations (Fields et al., 2001) are the "very" or "extremely" categories in the five-point semantic scale.

A total of 931 interviews were collected along with 755 estimates of internal vibration exposure. Therefore 755 case studies were available for the analysis presented in this paper.

\subsection{Statistical analyses}

To examine the exposure-response relationships between vibration level and annoyance at different times of day, ordinal logit models (Klæboe et al., 2003) were used to generate parameter estimates for the annoyance thresholds (not at all, slightly, moderately, very, and extremely). The following equation was used to obtain the estimated exposure-response relationships from the estimated parameters and indicates the probability of obtaining vibration annoyance response greater than or equal to $j$ :

$$
P\left(Y \geq j \mid \mathbf{X}_{i}=\mathbf{x}_{i}\right)=1-\left(\left(e^{\hat{\tau}_{j}-\hat{\beta}^{\prime} \mathbf{x}_{i}}\right) /\left(1+e^{\hat{\tau}_{j}-\hat{\beta}^{\prime} \mathbf{x}_{i}}\right)\right), \quad j \in[1, \ldots, J-1],
$$

where $\hat{\tau}_{j}$ indicates the $j$ th estimated threshold, and $\hat{\beta}$ is the estimated parameter for the exposure value. There are $J$ annoyance categories. $\mathbf{X}_{i}$ is a vector of exposure for an individual $i$.

\section{Results}

The time of day responses are related to the vibration levels experienced at that time of day. Table 1 shows the results from the ordinal logit model parameter estimations. These results are used to calculate the estimated exposure-response relationship in Eq. (1). Figure 1 shows the exposure-response relationship for day, evening, and night times. The curves indicate the percentage of residents expected to be highly annoyed by given vibration exposure levels from the railway. The gray bands indicate the $95 \%$ confidence intervals of the relationships between exposure and annoyance at different times of day. Figure 1 indicates that, e.g., with the same vibration exposure (rms $W_{k}$ ) of $0.004 \mathrm{~m} / \mathrm{s}^{2}, 4 \%$ are highly annoyed during the day, $7 \%$ during the evening, and $15 \%$ during the night. This means that many more people would be expected to be annoyed at night than during the day and evening at the same levels of exposure.

Table 1. Parameter estimates for railway traffic vibration annoyance during the day, evening, and night using ordinal logit model. ${ }^{\mathrm{a}}$

\begin{tabular}{|c|c|c|c|c|c|c|c|c|c|}
\hline \multirow{2}{*}{$\begin{array}{l}\text { Parameter } \\
\text { estimates }\end{array}$} & \multirow[b]{2}{*}{ Day } & \multicolumn{2}{|c|}{$95 \% \mathrm{CI}$} & \multirow[b]{2}{*}{ Evening } & \multicolumn{2}{|c|}{$95 \% \mathrm{CI}$} & \multirow[b]{2}{*}{ Night } & \multicolumn{2}{|c|}{$95 \% \mathrm{CI}$} \\
\hline & & Lower & Upper & & Lower & Upper & & Lower & Upper \\
\hline Threshold $(\hat{\tau})$ & & & & & & & & & \\
\hline $\begin{array}{l}\text { Highly annoying } \\
\text { Location }(\hat{\beta})\end{array}$ & 1.634 & 0.200 & 3.069 & 0.644 & -0.637 & 1.925 & -0.476 & -1.645 & 0.693 \\
\hline $\log _{10} \mathrm{rms} W_{k}$ & 0.650 & 0.129 & 1.171 & 0.821 & 0.348 & 1.276 & 0.931 & 0.498 & 1.365 \\
\hline
\end{tabular}

${ }^{\mathrm{a}}$ All results are statistically significant $(p<0.05) ; N=755$. 


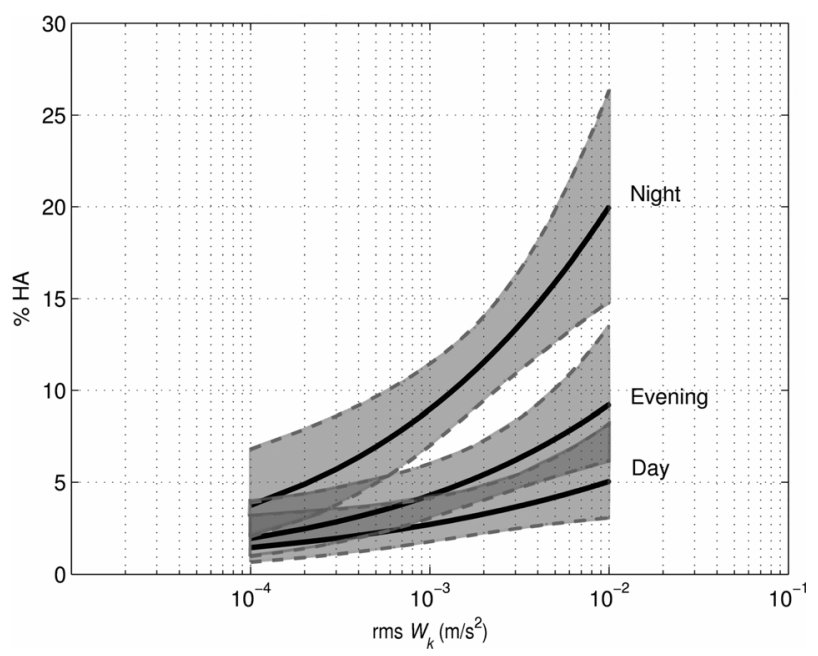

Fig. 1. Exposure-response curves for day, evening, and night vibration levels (vertical vibration rms $W_{k}$ ) and the proportion of people reporting high annoyance $(\% \mathrm{HA})$ due to railway vibration during these times of day. Curves are shown in their $95 \%$ confidence intervals.

Figure 2 shows the distance between the annoyance responses for the day, evening, and night. The distance between the annoyance responses $\left(w_{e}, w_{n}\right)$ is based on the distance between the curve for the daytime and the curve for each of the other times of day. These time period differences can be converted into time of day weights. For example, a rms $W_{k}$ of $0.01 \mathrm{~m} / \mathrm{s}^{2}$ in the day shows the same proportion of highly annoyed respondents as a rms $W_{k}$ of $0.0015 \mathrm{~m} / \mathrm{s}^{2}$ during the evening. Thus, a penalty should be applied to evening-time exposures when combining the vibration exposures in different periods into a single 24-h descriptor. Likewise, a rms $W_{k}$ of $0.01 \mathrm{~m} / \mathrm{s}^{2}$ in the daytime shows the same proportion of highly annoyed respondents as a $\mathrm{rms} W_{k}$ of only $0.0002 \mathrm{~m} / \mathrm{s}^{2}$ during the night. On the basis of these results a factor of $6.7\left(w_{e}\right)$ and a factor of $50\left(w_{n}\right)$ for evening and night-time exposures, respectively, should be applied when calculating an overall 24-h rms descriptor as indicated in Eqs. (2)-(4);

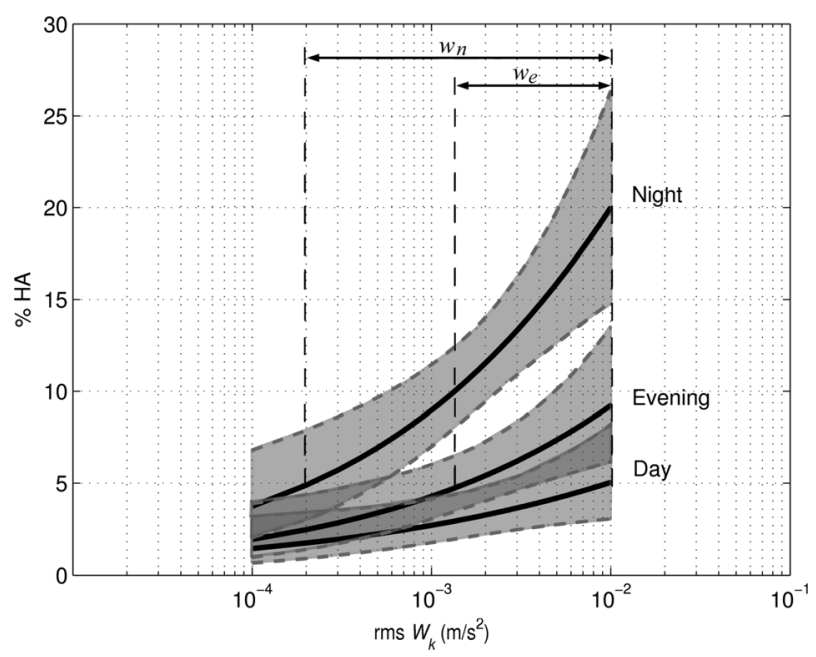

Fig. 2. Comparison of the proportion of people reporting high annoyance $(\% \mathrm{HA})$ during the day, evening, and night due to railway vibration (vertical vibration rms $W_{k}$ ). Curves are shown in their $95 \%$ confidence intervals. 


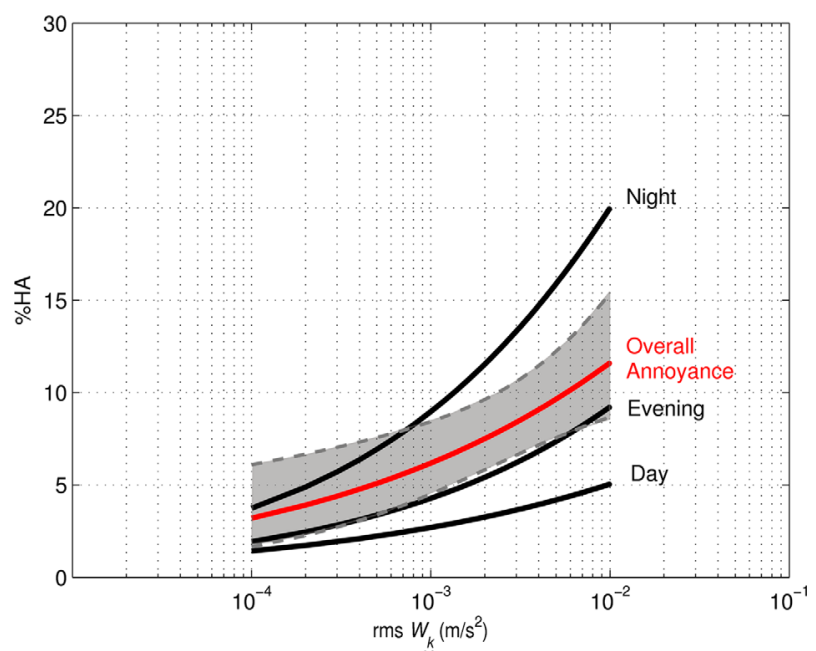

Fig. 3. (Color online) Comparison of the proportion of people reporting overall high annoyance $(\% \mathrm{HA})$ and high annoyance during the day, evening, and night due to railway vibration (vertical vibration rms $W_{k}$ ). Overall annoyance curve is shown in its $95 \%$ confidence intervals.

and where $a_{w, \text { den }}$ is the total day-evening-night frequency-weighted rms acceleration, $a_{w, 7: 00-19: 00}$ is the day frequency-weighted rms acceleration, $a_{w, 19: 00-23: 00}$ is the evening frequency-weighted rms acceleration, $a_{w, 23: 00-7: 00}$ is the night frequency-weighted rms acceleration and $w_{e}, w_{n}$ are the time of day weights. $w_{e}$ and $w_{n}$ expressed in decibels $(\mathrm{dB})$ are 8.3 and $17.0 \mathrm{~dB}$, respectively. However, as the values of the slopes are not the same for each period, $w_{e}$ and $w_{n}$ can vary slightly depending on the level of vibration exposure expressed as rms $W_{k}$,

$$
\begin{gathered}
\left(\left(w_{e} \cdot 0.0015\right)^{2}\right)^{0.5}=0.01 \rightarrow w_{e}=6.7, \\
\left(\left(w_{n} \cdot 0.0002\right)^{2}\right)^{0.5}=0.01 \rightarrow w_{n}=50, \\
a_{w, \text { den }}=\left[\left(a_{w, 7: 00-19: 00}\right)^{2}+\left(w_{e} \cdot a_{w, 19: 00-23: 00}\right)^{2}+\left(w_{n} \cdot a_{w, 23: 00-7: 00}\right)^{2}\right]^{0.5} .
\end{gathered}
$$

Figure 3 illustrates the exposure-response relationships at different times of day and the overall exposure-response relationship. These curves show that the overall annoyance curve falls between the night-time and evening-time exposure-annoyance curves. Therefore, the overall annoyance response is more closely related to the evening-time and night-time annoyance than to the daytime annoyance at the same rms level.

\section{Conclusions}

People's reactions due to railway vibration at different times of day have been investigated through analyses of time of day vibration levels and time of day annoyance. These analyses showed that vibration annoyance differs for different times of day and thus, time of day weightings should be applied when considering exposure-response relationships from railway vibration in residential environments. The analyses in time periods suggest that annoyance is greater in residential areas during evening and nighttime periods. The additional annoyance is equivalent to $17 \mathrm{~dB}$ for the night and $8 \mathrm{~dB}$ for the evening for a rms $W_{k}$ of $0.01 \mathrm{~m} / \mathrm{s}^{2}$ in the day. Therefore a 24-h metric $\left(a_{w, \text { den }}\right)$ incorporating such weights for periods 19:00-23:00 $\mathrm{h}$ and 23:00-7:00 $\mathrm{h}$ could be appropriate for predicting railway vibration annoyance. The comparison between time of day reactions shown in this paper should be taken into account by policy makers, 
environmental health practitioners, and planners for an optimal assessment and reduction of annoyance due to railway vibration.

\section{Acknowledgments}

This research was funded by the Department for Environment, Food and Rural Affairs (Defra) UK. The survey data were collected under the supervision of A. T. Steele (SHUSU).

\section{References and links}

Arnberg, P. W., Bennerhult, O., and Eberhardt, J. L. (1990). "Sleep disturbances caused by vibrations from heavy road traffic,” J. Acoust. Soc. Am. 88(3), 1486-1493.

British Standards Institution (2008). "Guide to evaluation of human exposure to vibration in buildings. Vibration sources other than blasting," BS 6472-1, London.

Condie, J., Whittle, N., Brown, P., and Waddington, D. (2009). "The development of a social survey questionnaire to investigate human response to vibration in residential environments," in Proceedings of Euronoise, Edinburgh.

EU/DG Environment (2002). "Directive for the assessment and evaluation of environmental noise," Directive 2002/2049/EC, Brussels.

Fields, J. M. (1986a). "An evaluation of study design for estimating a time-of-day noise weighting," NASA Report No. CR-178062, Hampton, VA.

Fields, J. M. (1986b). "The relative effect of noise at different times of day: An analysis of existing survey data," NASA Report No. CR-3965, Hampton," VA.

Fields, J. M., de Jong, R. G., Gjestland, T., Flindell, I. H., Job, R. F. S., Kurra, S., Lercher, P., Vallet, M., Guski, R., Felscher-Suhr, U., and Schuemer, R. (2001). "Standardized general-purpose noise reaction questions for community noise surveys: Research and a recommendation," J. Sound Vib. 242, 641-679. International Organization for Standardization (1997). "Mechanical vibration and shock-Evaluation of human exposure to whole-body vibration-Part1: General requirements," ISO 2631-1, Geneva, Switzerland.

International Organization for Standardization (2003). "Acoustics— assessment of noise annoyance by means of social and socio-acoustic surveys," ISO/TS 15666, Geneva, Switzerland.

Klæboe, R., and Fyhri, A. (1999). "People's reactions to vibrations in dwellings from road and rail (summary in English)," Institute of Transport Economic, Oslo, Norway.

Klæboe, R., Turunen-Rise, I., Harvik, L., and Madshus, C. (2003). "Vibration in dwellings from road and rail traffic-Part II: Exposure-effect relationships based on ordinal logit and logistic regression models," Appl. Acoust. 64, 89-109.

Miedema H. M. E., Vos, H., and de Jong, R. G. (2000). "Community reaction to aircraft noise: Time-ofday penalty and tradeoff between levels of overflights," J. Acoust. Soc. Am. 107, 3245-3253.

Miedema, H. M. E., and Oudshoorn, C. G. M. (2001). "Annoyance from transportation noise: relationships with exposure metrics DNL and DENL and their confidence intervals," Environ. Health Persp. 109, 409-416.

Ögren, M., and Öhrström, E. (2009). "Effects of railway noise and vibrations on sleep-experimental studies within the Swedish research program TVANE," in Proceedings of Euronoise, Edinburgh.

Öhrström, E., Ögren, M., and Jerson, T. (2009). "Effects of railway noise and vibration in combination: field and laboratory studies," in Proceedings of Euronoise, Edinburgh.

Öhrström, E. (1997). "Effects of exposure to railway noise — a comparison between areas with and without vibration," J. Sound Vib. 205, 555-560.

Schreckenberg, D., and Meis, M. (2006). "Gutachten belästigung durch Fluglärm im Umfeld des Frankfurter Flughafens (A survey of annoyance due to aircraft noise in communities surrounding Frankfurt airport)," Endbericht Regionales Dialogforum Flughafen, Frankfurt. Waddington, D. C., Woodcock, J., Condie, J., Sica, G., Peris, E., Henning, S., Whittle, N., Moorhouse, A. T., Steele, A., Brown, P. A., and Adams, M. D. (2010). "Research into the human response to vibration from railways in residential environments," in Proceedings of Noise-Con, Baltimore. 